\title{
Manejos de irrigação e nitrogênio na produção de feijoeiro sob plantio direto ${ }^{1}$
}

\author{
Arthur Pacheco ${ }^{2}$, Gabriel Queiroz de Oliveira ${ }^{3}$, Adriano da Silva Lopes ${ }^{2}$, Alessandro Santana Barbosa ${ }^{2}$
}

\begin{abstract}
Irrigation and nitrogen managements for producing bean plants under no-tillage system

Common bean has been cultivated by producers who have access to a wide range of technologies that allow a higher profitability in the winter. This study aimed at evaluating bean yield and its components, under no-tillage system, according to different irrigation and nitrogen fertilization managements, in Aquidauana, Mato Grosso do Sul State, Brazil. The experiment was carried out from June to September (2010), in the Universidade Estadual de Mato Grosso do Sul, in an Alfisol. The "Pérola" cultivar was sown in June and irrigated by conventional sprinkling. The experimental design was randomized blocks, with split-plots consisting of three blocks and two replications in each block. The plots consisted of three irrigation systems (Class "A" pan and Hargreaves-Samani and Penman-Monteith equations) and the subplots of four nitrogen fertilizing doses $\left(0 \mathrm{~kg} \mathrm{ha}^{-1}, 50 \mathrm{~kg} \mathrm{ha}^{-1}, 100 \mathrm{~kg} \mathrm{ha}^{-1}\right.$ and $\left.150 \mathrm{~kg} \mathrm{ha}^{-1}\right)$. Data were evaluated with the aid of variance analysis and compared by the Tukey test $(5 \%)$ and regression models. Bean plants reached the highest grain yield and number of pods per plant when the Class "A" pan irrigation system was used. Nitrogen doses did not affect bean yield.
\end{abstract}

KEY-WORDS: Phaseolus vulgaris L.; evapotranspiration; Class "A" pan; urea.

\section{INTRODUÇÃO}

No Brasil, o feijoeiro (Phaseolus vulgaris L.) é uma das mais importantes culturas agrícolas, sendo, comumente, cultivado em todos os Estados brasileiros, por pequenos e médios produtores, e seu cultivo realizado em todas as épocas do ano, com destaque para o inverno, quando se utiliza a irrigação como principal tecnologia (Sousa et al. 2009).

De acordo com Monteiro et al. (2010), as mudanças climáticas globais resultaram em uma ten-

\section{RESUMO}

O feijoeiro vem sendo cultivado por produtores que dispõem dos mais variados níveis de tecnologia, os quais permitem que a cultura alcance maior rentabilidade no inverno. Este trabalho objetivou avaliar a produtividade do feijoeiro e seus componentes, em razão de diferentes manejos de irrigação e adubação nitrogenada, em plantio direto, em Aquidauana (MS). O experimento foi conduzido de junho a setembro de 2010 , na Universidade Estadual de Mato Grosso Sul, em Argissolo Vermelho-Amarelo distrófico. Utilizou-se a cultivar Pérola, semeada em junho e irrigada por aspersão convencional. $\mathrm{O}$ delineamento experimental utilizado foi em blocos casualizados, com parcelas subdivididas, compostas por três blocos e duas replicações dentro de cada bloco. As parcelas foram compostas por três manejos de irrigação (tanque Classe "A" (TCA), equação de Hargreaves-Samani e equação de Penman-Monteith) e as subparcelas por quatro doses de adubação nitrogenada (0 kg ha ${ }^{-1}, 50 \mathrm{~kg} \mathrm{ha}^{-1}, 100 \mathrm{~kg} \mathrm{ha}^{-1}$ e $\left.150 \mathrm{~kg} \mathrm{ha}^{-1}\right)$. Os dados foram submetidos à análise de variância e comparados pelo teste Tukey (5\%) e modelos de regressão. O feijoeiro obteve as maiores produtividades de grãos e número de vagens por planta utilizando-se o manejo de irrigação com TCA. Não houve influência das doses de nitrogênio para os parâmetros produtivos do feijoeiro.

PALAVRAS-CHAVE: Phaseolus vulgaris L.; evapotranspiração; tanque Classe "A"; ureia.

dência para maior consciência ambiental, incluindo o uso sustentável de recursos naturais como a água. Portanto, o manejo adequado da cultura do feijão pode trazer benefícios tanto para o meio ambiente como para o rendimento da cultura. Dentre as técnicas de manejo recomendadas para a cultura, destacam-se a irrigação e a adubação nitrogenada.

Dentre os manejos de irrigação, destacam-se o monitoramento do teor de água no solo com o uso de tensiômetro e/ou reflectometria, sendo estes de difícil utilização para o agricultor, e a estimativa

1. Trabalho recebido em abr./2012 e aceito para publicação em set./2012 (nº registro: PAT 17883).

2. Universidade Estadual de Mato Grosso do Sul (UEMS), Unidade Universitária de Aquidauana, Aquidauana, MS, Brasil. E-mails: arthur_ap@hotmail.com, lopes@uems.br, santanabarbosa@hotmail.com. 
da evapotranspiração da cultura (ETc), que necessita da evapotranspiração de referência (ETo) e do coeficiente de cultura (kc) (Bernardo et al. 2006). No entanto, existem vários métodos para o cálculo da ETo, com destaque para o de Penman-Monteith (PM), Hargreaves-Samani (HS) e tanque Classe "A" (TCA), sendo que cada um deles apresenta particularidades específicas, que podem subestimar ou superestimar a quantidade de água necessária para a cultura, em determinada região (Carvalho et al. 2011).

Para o bom desenvolvimento da cultura, a nutrição mineral é um fator a ser considerado, principalmente quando se trata de agricultura irrigada, na qual a cultura tem melhores condições de expressar seu potencial produtivo quando realizado o fornecimento de nitrogênio em quantidade adequada, propiciando alta atividade fotossintética e crescimento vegetativo (Biscaro et al. 2011). Por tratar-se de uma leguminosa, grande parte do nitrogênio demandado pelo feijoeiro é suprida pela associação com bactérias do gênero Rhizobium, contudo, a quantidade fornecida por este processo, normalmente, é insuficiente, necessitando ser complementada (Silveira et al. 2003).

Existem vários trabalhos que apontam as doses de nitrogênio em cobertura mais eficientes para a cultura, no entanto, ressalta-se que as respostas do feijoeiro, diante destas doses, é dependente de vários fatores, como as condições físicas, químicas e biológicas do solo, bem como da fonte e forma de aplicação. Em trabalho desenvolvido por Oliveira et al. (2010a), em Argissolo, verificou-se que a maior produtividade do feijoeiro é alcançada aplicando-se a dose de $100 \mathrm{~kg} \mathrm{ha}^{-1}$ de N, na forma de ureia. Contudo, Cunha et al. (2011), estudando a aplicação de nitrogênio em cobertura em Latossolo, recomendam a aplicação de $150-160 \mathrm{~kg}$ de $\mathrm{N} \mathrm{ha}^{-1}$, para a máxima produtividade de grãos.

O feijoeiro destaca-se como uma das principais culturas anuais em adaptação ao plantio direto, caracterizado por proporcionar maior incremento de cobertura vegetal sobre a superfície do solo, favorecendo vários fatores de cultivo, como o amortecimento da energia do impacto das gotas da chuva e da irrigação sobre o solo, e minimizando a perda de água por evaporação (Bernardes et al. 2010).

Diante disso, este trabalho objetivou avaliar o feijoeiro de inverno submetido a diferentes manejos de irrigação, com base na estimativa da evapotrans- piração de referência e doses de nitrogênio em cobertura, no quinto ano de plantio direto.

\section{MATERIAL E MÉTODOS}

O experimento foi conduzido na área demonstrativa e experimental de agricultura da Universidade Estadual de Mato Grosso do Sul, em Aquidauana (MS) $\left(20^{\circ} 20^{\prime} \mathrm{S}, 55^{\circ} 48^{\prime} \mathrm{W}\right.$ e altitude média de $\left.174 \mathrm{~m}\right)$, entre junho e setembro de 2010. O clima da região, segundo a classificação de Köppen, foi descrito como Aw, definido como clima tropical quente subúmido, com estação chuvosa no verão e seca no inverno e precipitação média anual de $1.200 \mathrm{~mm}$. A temperatura média e a umidade relativa, no decorrer da pesquisa, foram de $23,1^{\circ} \mathrm{C}$ e $56,9 \%$, respectivamente.

O solo da área foi classificado como Argissolo Vermelho-Amarelo distrófico, fisicamente profundo e moderadamente drenado (Embrapa 2006).

O delineamento experimental utilizado foi em blocos casualizados, em esquema de parcelas subdivididas, utilizando-se três blocos e duas replicações dentro de cada bloco. Os tratamentos empregados nas parcelas corresponderam a três manejos de irrigação baseados em métodos de estimativa da evapotranspiração de referência (ETo). Nas subparcelas, os tratamentos testados foram quatro doses de nitrogênio aplicadas em cobertura $\left(0 \mathrm{~kg} \mathrm{ha}^{-1}, 50 \mathrm{~kg} \mathrm{ha}^{-1}\right.$, $100 \mathrm{~kg} \mathrm{ha}^{-1}$ e $150 \mathrm{~kg} \mathrm{ha}^{-1}$ ).

Os manejos de irrigação consistiram em:

a) Método de Penman-Montheith FAO-56 (PM): Recomendado pela FAO, com resistência estomática de $70 \mathrm{~s} \mathrm{~m}^{-1}$, altura da grama fixada em $0,12 \mathrm{~m}$ e albedo de $23 \%$, cuja estimativa se dá utilizando-se a seguinte equação (Allen et al. 1998):

$$
\mathrm{ETo}_{(\mathrm{PM})}=\frac{0,408 \Delta(\mathrm{Rn}-\mathrm{G})+\gamma\left(\frac{900 \mathrm{U}_{2}}{\mathrm{~T}+273}\right)(\text { es - ea })}{\Delta+\gamma\left(1+0,34 \mathrm{U}_{2}\right)},
$$

em que $\mathrm{ETo}_{(\mathrm{PM})}=$ evapotranspiração de referência, pelo método PM $\left(\mathrm{mm} \mathrm{d}^{-1}\right) ; \mathrm{Rn}=$ saldo de radiação $\left(\mathrm{MJ} \mathrm{m}^{-2} \mathrm{~d}^{-1}\right) ; \mathrm{G}=$ fluxo de calor no solo $\left(\mathrm{MJ} \mathrm{m}^{-2} \mathrm{~d}^{-1}\right)$; $\Delta=$ declinação da curva de saturação do vapor da água $\left(\mathrm{kPa}^{\circ} \mathrm{C}^{-1}\right) ; \mathrm{U}_{2}=$ velocidade média do vento, $2,0 \mathrm{~m}$ acima da superfície do solo $\left(\mathrm{m} \mathrm{s}^{-1}\right) ; \mathrm{T}=$ temperatura média do ar $\left({ }^{\circ} \mathrm{C}\right) ; \mathrm{e}_{\mathrm{s}}=$ pressão de saturação de vapor $(\mathrm{kPa}) ; \mathrm{e}_{\mathrm{a}}=$ pressão atual de vapor $(\mathrm{kPa})$; e $\gamma=$ constante psicrométrica $\left(\mathrm{kPa}^{\circ} \mathrm{C}^{-1}\right)$.

b) Método de Hargreaves-Samani (HS): Desenvolvido na Califórnia, em condições semiáridas, a 
partir de dados obtidos em lisímetros com gramado e descrito conforme a equação $\mathrm{ETo}_{(\mathrm{HS})}=0,0135 \mathrm{kt} \mathrm{Ra}$ $\left(\mathrm{T}_{\max }-\mathrm{T}_{\min }\right)^{0,5}(\mathrm{~T}+17,8)$ (Pereira et al. 1997), em que $\mathrm{ETo}_{(\mathrm{HS})}=$ evapotranspiração de referência, segundo o método HS $\left(\mathrm{mm} \mathrm{d}^{-1}\right)$; $\mathrm{kt}=$ coeficiente empírico, empregado em regiões continentais $(0,162) ; \mathrm{Ra}=$ radiação extraterrestre $\left(\mathrm{mm} \mathrm{d}^{-1}\right) ; \mathrm{T}=$ temperatura média do ar $\left({ }^{\circ} \mathrm{C}\right) ; \mathrm{T}_{\max }=$ temperatura máxima do ar $\left({ }^{\circ} \mathrm{C}\right)$; e $\mathrm{T}_{\min }=$ temperatura mínima do ar $\left({ }^{\circ} \mathrm{C}\right)$.

c) Método do tanque Classe "A" (TCA): Constituído por um tanque cilíndrico com chapa de aço galvanizado, com 1,21 m de diâmetro e 0,255 m de profundidade, de cor aluminizada, colocado em cima de um estrado de madeira e posicionado a 15,0 cm do solo, em área gramada, com borda de 10,0 m. Colocou-se água dentro do tanque, sendo o seu nível medido em um poço tranquilizador de $0,25 \mathrm{~m}$ de altura e $0,1 \mathrm{~m}$ de diâmetro, cuja borda foi afixada a um parafuso micrométrico, medindo-se variações mínimas de até $0,01 \mathrm{~mm}$ de evaporação de água. Na parte inferior do poço, há um orifício que permite a entrada de água, para a realização das medições (Allen et al. 1998). A equação utilizada para este método é $\mathrm{ETo}_{(\mathrm{TCA})}=\mathrm{kp} \mathrm{ECA}$, em que $\mathrm{ETo}_{(\mathrm{TCA})}=$ evapotranspiração de referência, pelo método do TCA $\left(\mathrm{mm} \mathrm{d}^{-1}\right)$; ECA = evaporação observada no TCA $\left(\mathrm{mm} \mathrm{d}^{-1}\right)$; e $\mathrm{kp}=$ coeficiente do tanque $(0,75)$. O kp, como constante de 0,75 , foi extraído de tabela proposta por Allen et al. (1998), considerando-se a velocidade do vento inferior a $2,0 \mathrm{~m} \mathrm{~s}^{-1}$ e umidade relativa variando entre $40 \%$ e $70 \%$.

A evapotranspiração da cultura foi determinada utilizando-se o coeficiente de cultura, que variou de acordo com sua fenologia, sendo a fase vegetativa de 0,35 a 1,15 , a fase reprodutiva de 1,15 e a fase que compreende o enchimento de grãos e maturidade de 1,15 a 0,25 (Allen et al. 1998). A evapotranspiração da cultura foi calculada utilizando-se a equação $\mathrm{ETc}=\mathrm{ETo} \mathrm{kc}$, em que ETc $=$ evapotranspiração da cultura $\left(\mathrm{mm} \mathrm{d}^{-1}\right)$; ETo $=$ evapotranspiração de referência $\left(\mathrm{mm} \mathrm{d}^{-1}\right)$ e $\mathrm{kc}=$ coeficiente de cultura (adimensional).
O sistema de irrigação por aspersão convencional foi instalado no dia 11 de junho de 2010, três dias após a semeadura do feijoeiro. Para realizar os três manejos de irrigação, a área foi dividida em três blocos de 84,0 m x 24,0 m, espaçados em 12,0 m. As parcelas foram de 24,0 $\mathrm{m} \times 24,0 \mathrm{~m}$, distanciadas umas das outras em 6,0 m, no mesmo bloco. No interior das parcelas, estavam contidas as quatro subparcelas contendo os tratamentos de doses de nitrogênio, em duas replicações, totalizando oito subparcelas de 3 linhas $(0,45 \mathrm{~m}$ x 5,0 m), abrangendo uma área útil de $6,75 \mathrm{~m}^{2}$.

Antes da instalação do experimento, no dia 27 de março de 2010, foram coletadas amostras, à profundidade de $0,0-0,2 \mathrm{~m}$ e 0,2-0,4 m, para a realização da análise química do solo (Tabela 1) e da textura. $\mathrm{O}$ solo foi classificado como arenoso, por conter menos de $15 \%$ de argila, nas profundidades avaliadas.

Baseando-se nos resultados da análise do solo (Tabela 1) e nas recomendações de Sousa \& Lobato (2004), não houve necessidade da aplicação de calcário e, desta forma, foi utilizado, na adubação de semeadura, o formulado 04-20-20, totalizando $240 \mathrm{~kg} \mathrm{ha}^{-1}$.

Foi realizado, no dia 15 de março de 2010, o controle mecânico de plantas invasoras, com o uso de roçadora, principalmente para controle de Panicum maximum. No dia 26 de abril de 2010, foi efetuada aplicação química, com o uso do herbicida glyphosate, para eliminar as plantas daninhas remanescentes, que foram dessecadas na dose de $4 \mathrm{~L} \mathrm{ha}^{-1}$ do produto comercial contendo $360 \mathrm{~g}$ i.a. $\mathrm{L}^{-1}$.

A semeadura do feijoeiro ocorreu no dia 8 de junho de 2010, sendo considerado "feijão de inverno". O feijão foi semeado mecanicamente, utilizando-se a cultivar Pérola, com $0,45 \mathrm{~m}$ entre as linhas e sementes suficientes para a obtenção de 16 plantas $\mathrm{m}^{-1}$. A emergência das plântulas ocorreu 8 dias após a semeadura e foi realizada, aos 20 dias após a emergência (DAE), aplicação de $2 \mathrm{~L} \mathrm{ha}^{-1}$ do herbicida seletivo fluazifop-p-butílico + formasafen, contendo $125+125$ g i.a. $\mathrm{L}^{-1}$, para controle das

Tabela 1. Caracterização química da amostra do solo (Aquidauana, MS, 2010).

\begin{tabular}{|c|c|c|c|c|c|c|c|c|c|c|}
\hline Profundidade & \multirow{2}{*}{$\mathrm{pH}^{*}$} & $\mathrm{P}$ & M.O. & $\mathrm{K}$ & $\mathrm{Ca}$ & $\mathrm{Mg}$ & $\mathrm{Al}$ & $\mathrm{H}+\mathrm{Al}$ & $\mathrm{S}$ & $\mathrm{T}$ \\
\hline $\mathrm{m}$ & & $\mathrm{mg} \mathrm{dm}^{-3}$ & $\%$ & 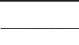 & & - & $\mathrm{cmol}$ & & & \\
\hline $0,0-0,2$ & 6,1 & 44,4 & 1,4 & 0,25 & 2,0 & 0,3 & 0,1 & 2,7 & 2,55 & 5,25 \\
\hline $0,2-0,4$ & 6,0 & 81,0 & 2,0 & 0,45 & 2,2 & 0,5 & 0,1 & 3,3 & 3,15 & 6,45 \\
\hline
\end{tabular}

* pH em água 1:2,5. 
plantas daninhas em pós-emergência. Aos 24 DAE (estágio V4), foi realizada a adubação nitrogenada de cobertura, com seus respectivos tratamentos.

A colheita foi efetuada manualmente, aos 94 DAE. O arranquio do feijoeiro foi realizado somente na área útil demarcada, que correspondia a três linhas de plantas por 5,0 $\mathrm{m}$ de comprimento $\left(6,75 \mathrm{~m}^{2}\right)$, contando-se todas as plantas de cada subparcela, sendo estas acondicionadas, para posterior separação e contagem das vagens, além da determinação da produtividade.

Foram avaliadas as seguintes variáveis: produtividade de grãos (PG), massa de 100 grãos (MCG), número de vagens por planta (NVP), número de grãos por vagem (NGV) e número de grãos por planta (NGP). Para as avaliações dos parâmetros, foram consideradas apenas as plantas coletadas na área das unidades experimentais. A produtividade de grãos e a massa de 100 grãos foram corrigidas para $13 \%$ de umidade, com o auxílio de um medidor de umidade de grãos (Agrosystem GAC $2100^{\circledR}$ ).

Os resultados foram submetidos à análise de variância e, quando os parâmetros foram significativos, utilizou-se o teste de comparação de médias Tukey (5\%), para o fator irrigação, e análise de regressão, para as doses de nitrogênio.

\section{RESULTADOS E DISCUSSÃO}

O manejo de irrigação, com base no método do tanque Classe "A" (TCA), propiciou os maiores valores de evapotranspiração máxima, média e mínima da cultura $\left(11,21 \mathrm{~mm} \mathrm{dia}^{-1}, 4,45 \mathrm{~mm} \mathrm{dia}^{-1} \mathrm{e}\right.$ $0,83 \mathrm{~mm} \mathrm{dia}^{-1}$, respectivamente) e lâmina de irrigação (380,60 mm) e o menor turno de rega (3,71 dias), no período do experimento. Verificou-se que os menores valores de evapotranspiração máxima e média foram encontrados com o método Penmam-Monteith (PM), com valores de $6,35 \mathrm{~mm} \mathrm{~d}^{-1}$ e $3,09 \mathrm{~mm} \mathrm{~d}^{-1}$ (Tabela 2).
Lopes et al. (2004) destacaram que, em Jaboticabal (SP), sob o manejo de irrigação com TCA, a lâmina total aplicada foi de 351,82 mm. Em 2007, Lopes et al. (2011) obtiveram, para as lâminas totais aplicadas (precipitação + irrigação), em experimento nesta mesma área, valores de 410,5 mm e 431,1 mm, para os manejos com HS e TCA, respectivamente, sendo que a precipitação correspondeu a $80,6 \mathrm{~mm}$.

A maior ETc $\left(11,21 \mathrm{~mm} \mathrm{~d}^{-1}\right)$ foi encontrada no manejo com TCA, aos 66 DAE, quando o feijoeiro encontrava-se no estágio R7 (Figura 1). A estimativa com TCA apresentou, no decorrer do ciclo do feijoeiro, grandes variações, com altos picos de evapotranspiração, em comparação aos métodos HS e PM. Segundo Vescove \& Turco (2005), o método TCA superestimou a evapotranspiração de referência (ETo) em 26\%, no período verão-outono, e 24\%, no período inverno-primavera, em relação ao método padrão da FAO (Penman-Monteith), em Araraquara (SP). Oliveira et al. (2010b) reforçaram este argumento, relatando que, na região norte do Estado da Bahia, os métodos de estimativa da ETo que utilizam como variável de entrada a temperatura do ar e a radiação solar global tiveram desempenho melhor do que o método TCA.

Em pesquisa realizada no Norte Fluminense (RJ), Mendonça et al. (2003) constataram que o método Hargreaves-Samani apresentou baixa precisão. No entanto, na Bacia do Rio Jacupiranga (SP), Borges \& Mendiondo (2007) encontraram alta precisão e sugeriram o uso da equação de Hargreaves-Samani para a estimativa da ETo, visto que o método demanda somente dados de temperatura do ar e radiação solar extraterrestre, conjugando simplicidade e exequibilidade.

A análise referente aos parâmetros do feijoeiro revelou que somente a produtividade de grãos e o número de vagens por planta foram influenciados pelos manejos de irrigação. As doses de nitrogênio não influenciaram nos parâmetros avaliados, no en-

Tabela 2. Evapotranspiração máxima (ETcmax), média (ETcmed) e mínima (ETcmin), lâmina de irrigação (LI), lâmina total (LT) e turno de rega (TR), em função do manejo de irrigação, durante o ciclo do feijoeiro (Aquidauana, MS, 2010).

\begin{tabular}{|c|c|c|c|c|c|c|}
\hline \multirow{2}{*}{$\begin{array}{c}\text { Manejo de } \\
\text { irrigação }\end{array}$} & ETcmax & ETcmed & ETcmin & LI & $\mathrm{LT}^{1}$ & \multirow{2}{*}{$\frac{\mathrm{TR}}{\mathrm{d}}$} \\
\hline & & $-\mathrm{mm} \mathrm{d}^{-1}$ & & 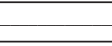 & 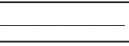 & \\
\hline TCA & 11,21 & 4,45 & 0,83 & 380,60 & 399,41 & 3,71 \\
\hline HARG & 6,55 & 3,47 & 0,76 & 282,40 & 301,21 & 4,76 \\
\hline PM & 6,35 & 3,09 & 0,79 & 245,60 & 264,41 & 5,34 \\
\hline
\end{tabular}

${ }^{1}$ Irrigação + chuva. 


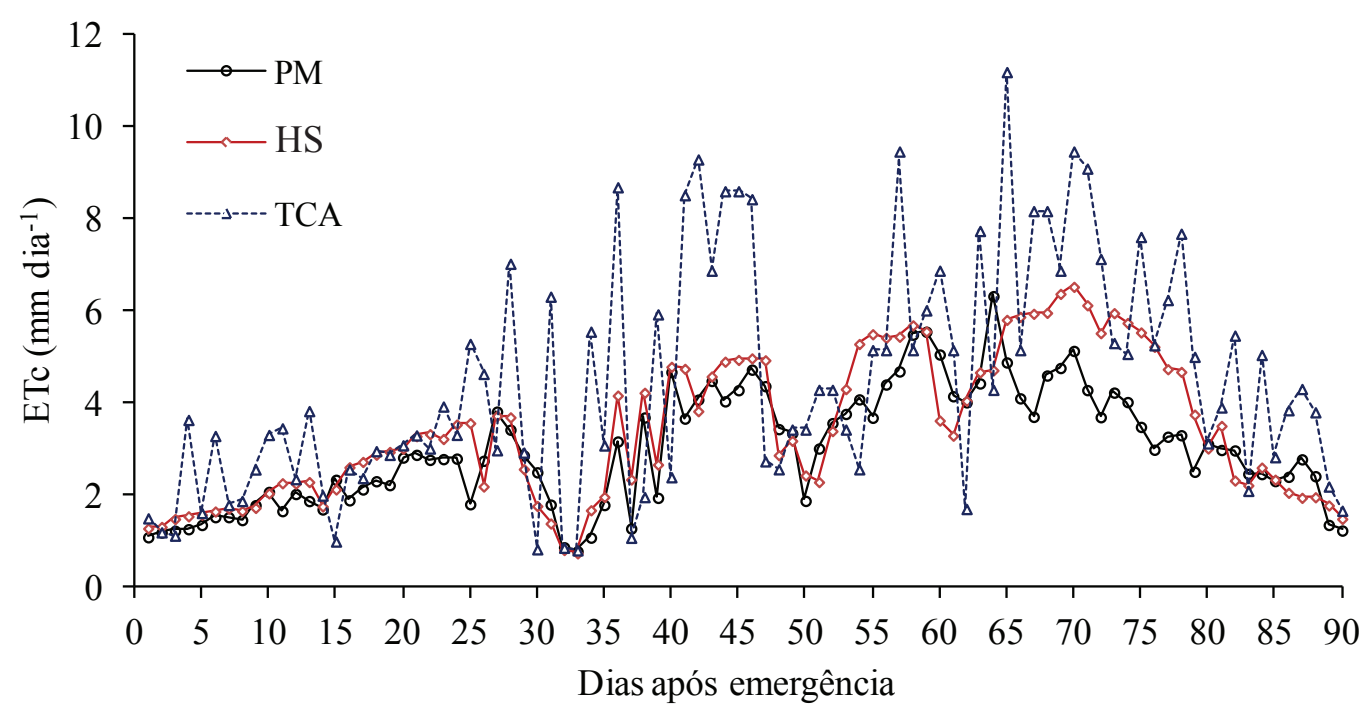

Figura 1. Evapotranspiração da cultura do feijoeiro, utilizando-se o manejo com tanque Classe "A" (TCA), Hargreaves-Samani (HS) e Penman-Monteith (PM) (Aquidauana, MS, 2010).

tanto, houve interação significativa entre os fatores manejos de irrigação e doses de nitrogênio, para os parâmetros massa de 100 grãos, número de grãos por planta e número de grãos por vagem.

Os maiores valores de produtividade de grãos e número de vagens por planta foram obtidos com o manejo TCA e diferiram dos métodos HS e $\mathrm{PM}$, os quais não diferiram entre si (Tabela 3). No método TCA, observou-se produtividade de grãos de $3.253,9 \mathrm{~kg} \mathrm{ha}^{-1}$, encontrando-se diferenças de $839,8 \mathrm{~kg} \mathrm{ha}^{-1}$ e $995,0 \mathrm{~kg} \mathrm{ha}^{-1}$, quando comparado aos métodos HS e PM, respectivamente.

Lopes et al. (2011) produziram 3.031,1 $\mathrm{kg} \mathrm{ha}^{-1}$ e $3.005,0 \mathrm{~kg} \mathrm{ha}^{-1}$, com os métodos TCA e HS, respectivamente, e ambos não diferiram entre si, destacando que os manejos de irrigação, a partir da estimativa da ETo pelo método do tanque Classe "A" e Hargreaves-Samani, proporcionam maiores valores

Tabela 3. Produtividade de grãos e vagens por planta, em função dos manejos de irrigação (Aquidauana, MS, 2010).

\begin{tabular}{ccc}
\hline $\begin{array}{c}\text { Manejo de } \\
\text { irrigação }^{1}\end{array}$ & $\begin{array}{c}\text { Produtividade de } \\
\text { grãos }\left(\mathrm{kg} \mathrm{ha}^{-1}\right)\end{array}$ & $\begin{array}{c}\text { Número de vagens } \\
\text { por planta }\end{array}$ \\
\hline TCA & $3.253,90 \mathrm{a}$ & $17,40 \mathrm{a}$ \\
HS & $2.414,10 \mathrm{~b}$ & $14,68 \mathrm{~b}$ \\
PM & $2.258,90 \mathrm{~b}$ & $13,19 \mathrm{~b}$ \\
\hline D.M.S. & 665,94 & 2,97 \\
\hline
\end{tabular}

Médias seguidas de letras iguais, na coluna, não diferem entre si pelo teste Tukey, a $5 \%$. ${ }^{1}$ Manejo com tanque Classe A (TCA), Hargreaves-Samani (HS) e PenmanMonteith (PM). de produtividade de grãos e número de grãos por vagem, em relação ao manejo por monitoramento da umidade do solo.

Diante da lâmina total aplicada no decorrer do experimento (Tabela 2), observou-se que o método TCA propiciou maior lâmina, em relação ao HS e PM, na ordem de $98,19 \mathrm{~mm}(24,6 \%)$ e $134,99 \mathrm{~mm}$ $(33,4 \%)$, respectivamente.

Apesar de os métodos HS e PM serem mais precisos, em relação à estimativa da ETo, os mesmos não propiciaram lâmina de irrigação final suficiente para o feijoeiro expressar seu máximo potencial produtivo e, assim, obter a máxima produtividade de grãos. Uma explicação possível talvez seja que o coeficiente de tanque ( $\mathrm{kp}$ ) de 0,75 , recomendado por Allen et al. (1998), não seja o mais indicado para o município de Aquidauana, e, desta forma, sugere-se que sejam efetuados estudos futuros de determinação do kp para condições regionais, uma vez que vários trabalhos apontam que o método TCA superestima a ETo (Oliveira et al. 2008, Barros et al. 2009, Oliveira et al. 2010b).

De acordo com Sousa et al. (2010), a utilização do coeficiente do tanque Classe " $A$ " fixo $(0,75)$, com o manejo da irrigação com TCA, superestima a ETo, quando comparado com o método de Penman-Monteith. Segundo Figueiredo et al. (2008), para um irrigante com disposição de assumir menor risco de produtividade de grãos do feijoeiro, a lâmina de irrigação deve ser superior a 440,0 mm. 
Com relação às doses de nitrogênio dentro de cada manejo de irrigação (Tabela 4), verificou-se que houve ajuste de modelos de regressão para os parâmetros massa de cem grãos, número de grãos por planta e número de grãos por vagem, quando utilizou-se o método de irrigação com TCA. Não houve resposta do nitrogênio para os modelos testados (linear, quadrático e cúbico) para estes parâmetros, quando utilizou-se o manejo de irrigação de PM, no entanto, o número de grãos por planta apresentou comportamento cúbico, quando aplicou-se doses de nitrogênio em cobertura e manejo de irrigação com HS (Tabela 4).

Por meio da equação quadrática $(\mathrm{p}>0,05)$, para explicar a massa de cem grãos em função das doses de nitrogênio, em relação ao método TCA, verificou-se que a menor massa de cem grãos foi encontrada com a dose estimada de $87,63 \mathrm{~kg} \mathrm{de} \mathrm{N} \mathrm{ha}^{-1}$ (Tabela 4). Este efeito talvez possa ser explicado pelo maior número de grãos por vagem promovidos pela interação do TCA e doses de nitrogênio de
$100 \mathrm{~kg} \mathrm{ha}^{-1}$, influenciando, negativamente, na massa de grãos.

Em experimento conduzido por Oliveira et al. (2009), a massa de cem grãos foi influenciada pela associação entre as lâminas de irrigação e as doses de nitrogênio, e a melhor associação se deu entre a lâmina de 30,5 mm e a aplicação de $100 \mathrm{~kg}$ de $\mathrm{N} \mathrm{ha}^{-1}$. Meira et al. (2005) salientaram que a massa de cem grãos tem, em média, 27,1 g e não apresenta efeito significativo, tanto das doses como das épocas de aplicação de nitrogênio. Este parâmetro apresenta característica de pouca variação percentual decorrente das alterações no meio de cultivo (Crusciol et al. 2003).

A irrigação promovida pelo método HS resultou em número de grãos por planta ajustado ao modelo de regressão cúbico, e a proporcionada pelo método TCA foi explicada pelos modelos quadrático e cúbico (Tabela 4). Uma possível explicação para este efeito significativo dos modelos é que ambos os métodos de irrigação (HS e TCA) contribuíram

Tabela 4. Massa de 100 grãos, número de grãos por planta e grãos por vagem, em função de doses de nitrogênio, utilizando-se os métodos TCA, HS e PM (Aquidauana, MS, 2010).

\begin{tabular}{|c|c|c|c|c|}
\hline Parâmetros & irrigação $^{1}$ & Regressão & Modelo & $\mathrm{R}^{2}$ \\
\hline \multirow{9}{*}{$\begin{array}{l}\text { Massa de } \\
100 \text { grãos }\end{array}$} & \multirow{3}{*}{ HS } & Linear & $y=27,40-0,0085 x$ & $0,135^{\text {ns }}$ \\
\hline & & Quadrático & $y=27,43-0,01 x+10^{-5} x^{2}$ & $0,135^{\text {ns }}$ \\
\hline & & Cúbico & $y=27,23+0,05 x-0,001 x^{2}+5.10^{-6} x^{3}$ & $0,255^{\text {ns }}$ \\
\hline & \multirow{3}{*}{ PM } & Linear & $y=25,93-0,0005 x$ & $0,000^{\text {ns }}$ \\
\hline & & Quadrático & $y=25,58+0,02 x-10^{-4} x^{3}$ & $0,047^{\text {ns }}$ \\
\hline & & Cúbico & $y=25,65-0,0009 x+0,0003 x^{2}-2 \cdot 10^{-6} x^{3}$ & $0,056^{\text {ns }}$ \\
\hline & \multirow{3}{*}{ TCA } & Linear & $y=-26,27-0,0060 x$ & $0,029^{\text {ns }}$ \\
\hline & & Quadrático & $y=27,34-0,07 x+0,0004 x^{2}$ & $0,324 *$ \\
\hline & & Cúbico & $y=27,46-0,107 x+0,001 x^{2}-3 \cdot 10^{-6} x^{3}$ & $0,343 *$ \\
\hline \multirow{9}{*}{$\begin{array}{l}\text { Número de } \\
\text { grãos por } \\
\text { planta }\end{array}$} & \multirow{3}{*}{ HS } & Linear & $y=46,67+0,0143 x$ & $0,004^{\text {ns }}$ \\
\hline & & Quadrático & $y=47,52-0,037 x+0,00034 x^{2}$ & $0,009^{\text {ns }}$ \\
\hline & & Cúbico & $y=50,63-1,01 x+0,019 x^{2}-8 \cdot 10^{-5} x^{3}$ & $0,337 *$ \\
\hline & \multirow{3}{*}{ PM } & Linear & $y=49,76-0,1016 x$ & $0,111^{\text {ns }}$ \\
\hline & & Quadrático & $y=50,87-0,168 x+0,00044 x^{2}$ & $0,115^{\text {ns }}$ \\
\hline & & Cúbico & $y=49,94+0,125 x-0,005 x^{2}+2 \cdot 10^{-5} x^{3}$ & $0,130^{\mathrm{ns}}$ \\
\hline & \multirow{3}{*}{ TCA } & Linear & $\mathrm{y}=58,91+0,1149 x$ & $0,115^{\text {ns }}$ \\
\hline & & Quadrático & $y=51,03+0,587 x-0,0032 x^{2}$ & $0,288^{*}$ \\
\hline & & Cúbico & $y=52,96-0,016 x+0,008 x^{2}-5 \cdot 10^{-5} x^{3}$ & $0,339 *$ \\
\hline \multirow{9}{*}{$\begin{array}{l}\text { Número de } \\
\text { grãos por } \\
\text { vagem }\end{array}$} & \multirow{3}{*}{ HS } & Linear & $y=3,24-3 \cdot 10^{-5} x$ & $0,000^{\text {ns }}$ \\
\hline & & Quadrático & $y=3,349-0,0067 x+4 \cdot 10^{-5} x^{2}$ & $0,112^{\text {ns }}$ \\
\hline & & Cúbico & $y=3,45-0,03 x+7 \cdot 10^{-4} x^{2}-3 \cdot 10^{-6} x^{3}$ & $0,579 * *$ \\
\hline & \multirow{3}{*}{ PM } & Linear & $y=3,35-0,0031 x$ & $0,086^{\mathrm{ns}}$ \\
\hline & & Quadrático & $y=3,435-0,008 x+3 \cdot 10^{-5} x^{2}$ & $0,105^{\text {ns }}$ \\
\hline & & Cúbico & $y=3,40+0,003 x-2 \cdot 10^{-4} x^{2}+9 \cdot 10^{-7} x^{3}$ & $0,122^{\text {ns }}$ \\
\hline & \multirow{3}{*}{ TCA } & Linear & $\mathrm{y}=3,42+0,0059 \mathrm{x}$ & $0,220^{*}$ \\
\hline & & Quadrático & $y=3,247+0,016-7.10^{-5} x^{2}$ & $0,284 *$ \\
\hline & & Cúbico & $y=3,30-0,0019 x+3 \cdot 10^{-4} x^{2}-2 \cdot 10^{-6} x^{3}$ & $0,320 *$ \\
\hline
\end{tabular}


para maior teor de água, ao longo do ciclo do feijoeiro, apresentando lâmina de irrigação superior a 300,0 mm (Tabela 2).

Em estudo conduzido por Alvarez et al. (2005), em 1999 e 2000, os resultados mostraram que as doses de nitrogênio influenciaram no número de grãos por planta, ajustando-se a uma função linear. Estes resultados foram confirmados por Teixeira et al. (2005), que, também, verificaram aumento no número de grãos por planta, com o aumento da adubação nitrogenada. Entretanto, Oliveira et al. (2009) observaram que, em estudo realizado na mesma área, em 2007, os resultados para número de grãos por planta não foram influenciados pelas doses de nitrogênio em cobertura.

Verificou-se que os modelos de regressão para número de grãos por planta, em função das doses de nitrogênio, utilizando-se o método TCA, foram o quadrático e o cúbico (Tabela 4). Andrade et al. (1998) relataram que este componente, geralmente, não apresenta influência da adubação, por ser esta uma característica da variedade.

Segundo Soratto et al. (2004), a aplicação de nitrogênio em cobertura não causa grande variação no número de grãos por vagem. Contudo, no presente trabalho, o manejo com TCA forneceu maior lâmina de irrigação (Tabela 2), fato que pode ter contribuído para o maior teor de água no solo e, com isto, maior absorção do nitrogênio do solo, via fluxo de massa, contribuindo para um maior número de grãos por vagem $(4,22)$, com aplicação de nitrogênio estimada em $117,86 \mathrm{~kg} \mathrm{ha}^{-1}$, pelo modelo quadrático.

\section{CONCLUSÕES}

1. O método de irrigação com tanque Classe "A" promoveu maior lâmina de irrigação, bem como as maiores produtividades de grãos e número de vagens, para o feijoeiro cultivado em plantio direto.

2. As doses de nitrogênio em cobertura não influenciaram na produtividade de grãos, massa de cem grãos, número de grãos por planta, número de grãos por vagem e número de vagens por planta.

\section{REFERÊNCIAS}

ALLEN, R. G. et al. Crop evapotranspiration: guidelines for computing crop water requirements. Rome: FAO, 1998. (Irrigation and drainage paper, 56).
ALVAREZ, A. C. C. et al. Resposta do feijoeiro à aplicação de doses e fontes de nitrogênio em cobertura no sistema de plantio direto. Acta Scientiarum Agronomy, Maringá, v. 27, n. 1, p. 69-75, 2005.

ANDRADE, M. J. B. et al. Resposta da cultura do feijoeiro à aplicação foliar de molibdênio e às adubações nitrogenadas de plantio e cobertura. Ciência e Agrotecnologia, Lavras, v. 22, n. 3, p. 499-508, 1998.

BARROS, V. R. et al. Avaliação da evapotranspiração de referência na região de Seropédica, Rio de Janeiro, utilizando lisímetro de pesagem e modelos matemáticos. Revista Brasileira de Ciências Agrárias, Recife, v. 4, n. 2, p. 198-203, 2009.

BERNARDES, T. G.; SILVEIRA, P. M.; MESQUITA, M. A. M. Produtividade do feijoeiro irrigado devido a reguladores de crescimento e culturas antecessoras de cobertura. Bragantia, Campinas, v. 69, n. 2, p. 371-375, 2010.

BERNARDO, S.; SOARES, A. A.; MANTOVANI, E. C. Manual de irrigação. 8. ed. Viçosa: UFV, 2006.

BISCARO, G. A. et al. Nitrogênio em cobertura e molibdênio via foliar no feijoeiro irrigado cultivado em solo de Cerrado. Acta Scientiarum Agronomy, Maringá, v. 33, n. 4, p. 665-670, 2011.

BORGES, A. C.; MENDIONDO, E. M. Comparação entre equações empíricas para estimativa da evapotranspiração de referência na Bacia do Rio Jacupiranga. Revista Brasileira de Engenharia Agrícola e Ambiental, Campina Grande, v. 11, n. 3, p. 293-300, 2007.

CARVALHO, L. G. et al. Evapotranspiração de referência: uma abordagem atual de diferentes métodos de estimativa. Pesquisa Agropecuária Tropical, Goiânia, v. 41, n. 3, p. 456-465, 2011.

CRUSCIOL, C. A. C. et al. Efeito do nitrogênio sobre a qualidade fisiológica, produtividade e características de sementes de feijão. Revista Brasileira de Sementes, Pelotas, v. 25, n. 1, p. 108-115, 2003.

CUNHA, P. C. R. et al. Fontes, formas de aplicação e doses de nitrogênio em feijoeiro irrigado sob plantio direto. Pesquisa Agropecuária Tropical, Goiânia, v. 41, n. 1, p. 80-86, 2011.

EMPRESA BRASILEIRA DE PESQUISA AGROPECUÁRIA (Embrapa). Sistema brasileiro de classificação de solos. Rio de Janeiro: Embrapa Solos, 2006.

FIGUEIREDO, M. G. et al. Lâmina ótima de irrigação do feijoeiro, com restrição de água, em função do nível de aversão ao risco do produtor. Acta Scientiarum Agronomy, Maringá, v. 30, n. 1, p. 81-87, 2008. 
LOPES, A. S. et al. Manejo de irrigação e nitrogênio no feijoeiro comum cultivado em sistema plantio direto. Revista Ciência Agronômica, Fortaleza, v. 42, n. 1, p. 5156, 2011.

LOPES, A. S. et al. Manejo da irrigação (tensiometria e balanço hídrico climatológico) para a cultura do feijoeiro em sistemas de cultivo direto e convencional. Engenharia Agrícola, Jaboticabal, v. 24, n. 1, p. 89-100, 2004.

MEIRA, F. A. et al. Doses e épocas de aplicação de nitrogênio no feijoeiro irrigado cultivado em plantio direto. Pesquisa Agropecuária Brasileira, Brasília, DF, v. 40, n. 4, p. 383-388, 2005.

MENDONÇA, J. C. et al. Comparação entre métodos de estimativa da evapotranspiração de referência (ETo) na região Norte Fluminense, RJ. Revista Brasileira de Engenharia Agrícola e Ambiental, Campina Grande, v. 7, n. 2, p. 275-279, 2003.

MONTEIRO, P. F. C.; ANGULO FILHO, R.; MONTEIRO, R. O. C. Efeitos da irrigação e da adubação nitrogenada sobre as variáveis agronômicas da cultura do feijão. Irriga, Botucatu, v. 15, n. 4, p. 386-400, 2010.

OLIVEIRA, G. M. et al. Comparação entre métodos de estimativa da evapotranspiração de referência na região norte da Bahia. Revista Brasileira de Agricultura Irrigada, Fortaleza, v. 4, n. 2, p. 104-109, 2010 b.

OLIVEIRA, G. Q. et al. Irrigação e doses de nitrogênio no feijoeiro de inverno, em sistema plantio direto, no município de Aquidauana - MS. Irriga, Botucatu, v. 14, n. 1, p. 54-67, 2009.

OLIVEIRA, G. Q. et al. Resposta do feijoeiro de inverno a manejos de irrigação e doses de nitrogênio em cobertura no sistema plantio direto. Agrarian, Dourados, v. 3, n. 7, p. 8-17, 2010a.

OLIVEIRA, L. M. M. et al. Evapotranspiração de referência na bacia experimental do riacho Gameleira, PE, utilizando-se lisímetro e métodos indiretos. Revista Brasileira de Ciências Agrárias, Recife, v. 3, n. 1, p. 5867, 2008.
PEREIRA, A. R.; VILLA NOVA, N. A.; SEDIYAMA, G. C. Evapo(transpi)ração. Piracicaba: FEALQ, 1997.

SILVEIRA, P. M.; BRAZ, A. J. B. P.; DIDONET, A. D. Uso do clorofilômetro como indicador da necessidade de adubação nitrogenada em cobertura no feijoeiro. Pesquisa Agropecuária Brasileira, Brasília, DF, v. 38, n. 9, p. 1083 1087, 2003.

SORATTO, R. P.; CARVALHO, M. A. C.; ARF, O. Teor de clorofila e produtividade do feijoeiro em razão da adubação nitrogenada. Pesquisa Agropecuária Brasileira, Brasília, DF, v. 39, n. 9, p. 895-901, 2004.

SOUSA, D. M. G.; LOBATO, E. Calagem e adubação para culturas anuais e semiperenes. In: SOUSA, D. M. G.; LOBATO, E. Cerrado, correção do solo e adubação. 2. ed. Brasília, DF: Embrapa, 2004. p. 283-315.

SOUSA, I. F. et al. Evapotranspiração de referência nos perímetros irrigados do Estado de Sergipe. Revista Brasileira de Engenharia Agrícola e Ambiental, Campina Grande, v. 14, n. 6, p. 633-644, 2010.

SOUSA, M. A. et al. Estresse hídrico e profundidade de incorporação do adubo afetando os componentes de rendimento do feijoeiro. Pesquisa Agropecuária Tropical, Goiânia, v. 39, n. 2, p. 175-182, 2009.

TEIXEIRA, C. M. et al. Palhadas e doses de nitrogênio no plantio direto do feijoeiro. Acta Scientiarum Agronomy, Maringá, v. 27, n. 3, p. 499-505, 2005.

VESCOVE, H. V.; TURCO, J. E. P. Comparação de três métodos de estimativa da evapotranspiração de referência para a região de Araraquara - SP. Engenharia Agrícola, Jaboticabal, v. 25, n. 3, p. 713-721, 2005. 